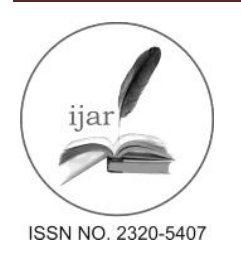

Journal homepage: http://www.journalijar.com

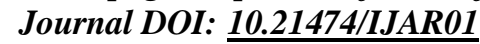

INTERNATIONAL JOURNAL

OF ADVANCED RESEARCH

RESEARCH ARTICLE

\title{
FABRICATION AND MECHANICAL BEHAVIOUR STUDY OF COCONUT COIR BASED POLYMER COMPOSITE.
}

\author{
Deepak Davis. \\ Department of Physics and Nanotechnology, SRM University, Chennai.
}

\section{Manuscript Info \\ ................................... \\ Manuscript History: \\ Received: 18 February 2016 \\ Final Accepted: 29 March 2016 \\ Published Online: April 2016 \\ Key words: \\ Coconut shell powder, \\ Coconut Coir, \\ Polymer matrix composite. \\ *Corresponding Author \\ Deepak Davis}

\begin{abstract}
As we know the composite materials using for the light weight application. We have selected polyester resin as matrix, coir fiber as fiber reinforcement and coconut shell powder as particle reinforcement. Coir fiber and coconut shell powder are agricultural by-products and thus they are eco-friendly and biodegradable constituents. Three different volume percentages of PMCs are made $(10 \%, 15 \%, 20 \%)$, so that we can analyze the effect of increase of reinforcements in polyester resin and to determine the optimum mix of reinforcements in the matrix phase. There is a different type of fiberreinforced plastic processes and it is depends on many factors, such as type of reinforcement and matrix materials, size, shape, quantity, and cost.
\end{abstract}

Copy Right, IJAR, 2016. All rights reserved...

\section{Introduction:-}

Two or more constituent materials with highly significantly different chemical or physical properties, that when combined and produce a material with characteristics different from the individual components, then it is called Composite materials [4]. It is composed of two or more distinct phases such as matrix phase and dispersed phase it having bulk properties different from the any of the constituents [10]. Typical engineered composite materials include cements, concrete, Plastics reinforced such as fiber-reinforced polymer, Metal Matrix Composites, Ceramic Matrix Composites, Fiber glass, Plywood, Brick, Carbon fiber etc. The properties of a Natural fiber-reinforced composite depend many on the parameters, such as fiber strength, modulus, length and orientation of fiber, also the fiber-matrix interfacial bond strength, It is critical for high mechanical properties of composites and effective stress transfer from the matrix to the fiber [7]. Main reason to use coir fibers as reinforcement in polymer-matrix composites is an abundant, versatile, renewable, cheap, and biodegradable [13]. Coir is tested as filler or reinforcement in different composite materials $[3,9]$. Testing says that coconut coir has lowest thermal conductivity also bulk density properties. Also it is reduced the thermal conductivity of the specimens (composite) and getting lightweight product and solve the environment and energy concern [8, 1]. Coir fiber-polyester composites were tested in helmets, roofing and post-boxes [14]. The coir loading to the composite is ranging from $9 \mathrm{wt} \%$ to $15 \mathrm{wt} \%$, also it have a flexural strength about $38 \mathrm{MPa}$. But only a moderate increase in the values of the mechanical properties. Fibers provide increased stiffness and tensile capacity to the composites and giving them the mechanical characteristics [2].

The resin offers high compressive strength and binds the fibers into firm matrix [11]. General advantages of coconut fibers are they are moth-proof, resistant to fungi and rot, provide excellent insulation to external parameters like temperature and sound, [6]. However, very limited work has been done on effect of volume \% of reinforcements to the mechanical behavior of the polyester composites [12]. The main objective of the coir fiber and coconut shell powder was to investigate the effect of mechanical behavior of the resulting composites [5]. 


\section{Material and Methods:-}

In this work we are using Polyester Resin $\left(300 \mathrm{~cm}^{3}\right)$, Coir Fiber $\left(1 \mathrm{~cm}-70 \mathrm{~cm}^{3}\right)$, Coconut Shell Powder $(300 \mu \mathrm{m}$ size, $70 \mathrm{~cm}^{3}$ ), as the key materials and Cobalt is used as Accelerator also we are using MEKP (Methyl Ethyl Kenton Peroxide) as the hardener.

Rectangular mould with square cross section having dimensions $15 \mathrm{~cm} \times 15 \mathrm{~cm} \times 6 \mathrm{~cm}$ is made from plywood. Plywood is chosen to made mould because of its adequate surface finish, strength and easiness to cut in any dimensions. Then inner walls of mould glued by OHP (Over Head Project) sheet for easy detachment of specimen from the mould after curing. There are many specialized processes available, here we are using the most commonly used commercial process is called hand lay-up process. The entire sample are divided in to 3 samples in such a way that sample- 1 contains $10 \%$ particle, fiber reinforcements each, sample- 2 contains $15 \%$ particle, fiber reinforcements each and sample- 3 contains $20 \%$ particle, fiber reinforcements each as given in the table 1 below.

Table 1: Amount of Constituents in Samples.

\begin{tabular}{|l|c|c|c|}
\hline & Polyester Resin $\left(\mathrm{cm}^{3}\right)$ & Coir Fiber $\left(\mathrm{cm}^{3}\right)$ & Coconut Shell Powder $\left(\mathrm{cm}^{3}\right)$ \\
\hline Sample-1 & 108 & 13.5 & 13.5 \\
\hline Sample-2 & 94.5 & 20.25 & 20.25 \\
\hline Sample-3 & 81 & 27 & 27 \\
\hline
\end{tabular}

The resin and coconut shell powder are added through the help of stirring. Then adequate amount of coir fiber mixed with that solution. After that, 10-12 drops of Cobalt accelerator added to the solution. After a constant stirring of 3 minutes, 10 drops of MEKP (Methyl Ethyl Kenton Peroxide) hardener is added. Hardener is mixed thoroughly mixed by stirring. Then the entire solution transferred slowly into the mould. After complete transfer, uniformly of coir fiber is distributed to the matrix with the help of a flat metal rod. There is no need of roller loading since there is no chance of entrapment of air bubbles in the matrix material as it is in liquid phase. After these processes, the sample is allowed to cure for 8 hours. After proper setting, composite product can be detached from mould box. The above procedure is to be followed to all the samples. Finally all the composite products allowed undergoing mechanical property testing.

\section{Result and Discussion:-}

ASTM (American Society for Testing and Materials) is an international organization for standards. It develops and producing many technical standards for a wide range of materials, products and systems. Now a day's more than 13,000 plus ASTM standards were used worldwide to improve the quality of product and enhance the safety requirements and facilitate. So in this work we are using the following ASTM standards for testing of polymer.

\section{ASTM D638:-}

ASTM D638 (Test Method for Tensile Properties of polymers) is the method used for examine the tensile properties of polymers. Tensile tests measure the how much force required to break the specimen and elongates to that breaking point. The stress-strain diagram is used to determine tensile modulus and it is often used to specify a material in design parts to withstand application force. UTM (Universal Testing Machine) is used to carry out the tensile strength test. Graphical representation of calculated values shown in fig.1

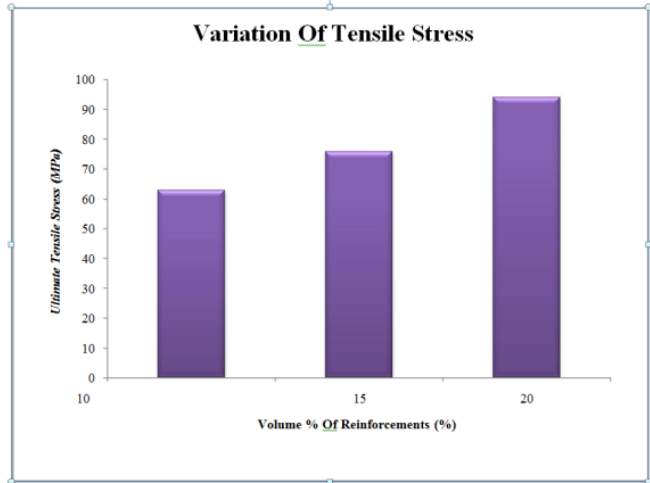

Fig. 1: Graphical Representation of Ultimate Tensile Stress. 
Table 2: Observation Table of Tensile Strength Test.

\begin{tabular}{|c|c|c|c|}
\hline Volume \% of Reinforcements & $\begin{array}{c}\text { Cross Sectional Area of } \\
\text { Specimen }\left(\mathrm{mm}^{2}\right)\end{array}$ & $\begin{array}{c}\text { Ultimate Tensile } \\
\text { Load ( N ) }\end{array}$ & $\begin{array}{c}\text { Ultimate Tensile } \\
\text { Stress }\left(\mathrm{N} / \mathrm{mm}^{2}\right)\end{array}$ \\
\hline 10 & 90 & 5675 & 63.05 \\
\hline 15 & 90 & 6830 & 75.88 \\
\hline 20 & 90 & 8465 & 94.05 \\
\hline
\end{tabular}

The tensile stress is maximum for $20 \%$ volume sample. Tensile stress reduces with the reduction of reinforcements. This is because of the fact that fibers have the appreciable capability to carry tensile loads. Here, one advantage of coir fiber is highlighted.

\section{ASTM D695:-}

ASTM D695 (Test Method for Compressive Properties of polymers) is standard is used to measure the compressive properties of a polymers. CTM (Compression Testing Machine) is used to carry out the compressive strength test. Place the specimen between the two plates of the testing machine. Apply an axial load at a uniform rate till failure and note down the maximum load at failure. This will be the maximum compressive load and from that compressive stress can be calculated. Graphical representation of calculated values shown in fig. 2

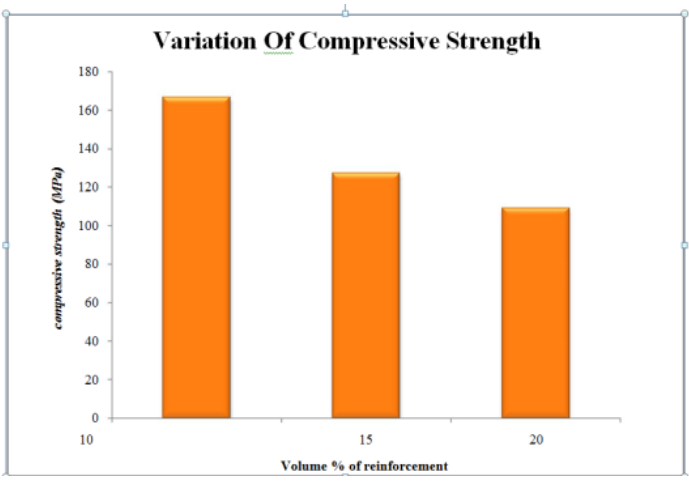

Fig. 2: Graphical Representation Maximum Compressive Stress.

Table 3: Observation Table of Compressive Strength Test.

\begin{tabular}{|c|c|c|c|}
\hline Volume \% of reinforcements & Cross Section Of Specimen & $\begin{array}{c}\text { Maximum Load At Failure } \\
(\mathrm{N})\end{array}$ & $\begin{array}{c}\text { Compressive } \\
\text { Strength }\left(\mathrm{N} / \mathrm{mm}^{2}\right)\end{array}$ \\
\hline 10 & $18 \mathrm{~mm} \times 18 \mathrm{~mm}$ & $54 \times 10^{3}$ & 166.67 \\
\hline 15 & $19 \mathrm{~mm} \times 19 \mathrm{~mm}$ & $46 \times 10^{3}$ & 127.40 \\
\hline 20 & $16 \mathrm{~mm} \times 16 \mathrm{~mm}$ & $28 \times 10^{3}$ & 109.37 \\
\hline
\end{tabular}

Compressive stress is maximum for $10 \%$ reinforced composites. Compressive stress decreases with increase of reinforcements. The reason behind this is there is a good wetting between the reinforcements and matrix and a strong interface is created which is lead to a strong bonding in $10 \%$ specimen. However, high percentage of reinforcements will result in poor wetting between the reinforcements and polyester matrix. It was found lead to the less area of reinforcements being bonded by the matrix.

\section{ASTM D790:-}

ASTM D790 (Test Method for Flexural Properties of polymers) is the test method used for examine the flexural properties of polymers. These calculations allow to choosing suitable materials for the application. It is related to the stiffness of the material. ASTM D790 is used to measure the flexural properties of a plastic. Many different test dimensions can be used based on the application but the most common is to test a 1/8 inch thick test bar. Graphical representation of calculated values shown in fig. 3 


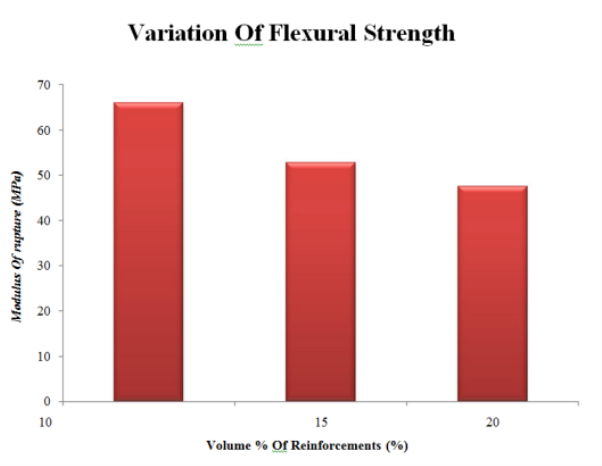

Fig. 3: Graphical Representation of Maximum Flexural Stress.

Table 4: Observation Table of Flexural Strength Test.

\begin{tabular}{|c|c|c|}
\hline Volume \% of Reinforcements & Maximum Load ( N ) & Modulus of Rupture ( N/mm $\left.{ }^{2}\right)$ \\
\hline 10 & 250 & 65.97 \\
\hline 15 & 200 & 52.78 \\
\hline 20 & 180 & 47.5 \\
\hline
\end{tabular}

Flexural strength also seems to be increased in 10\% sample because of the good wetting of resin and appreciably strong bond. In higher percentages of reinforcements, the composite will become more easy to deform and flexible

\section{ASTM D256:-}

ASTM D256 (Test Method for Impact Properties of polymers) is the test method used for examine the impact properties of polymers. Impact resistance of commercial grade polymer, is a function of the base resin of the impact modifiers and reinforcing agents. Environmental factors other than temperature also play a role in impact resistance. A pendulum and its track strikes on a notched. Polymeric materials that are sensitive to the stress concentrations at the notch it will do in izod test. Graphical representation of calculated values shown in fig.4

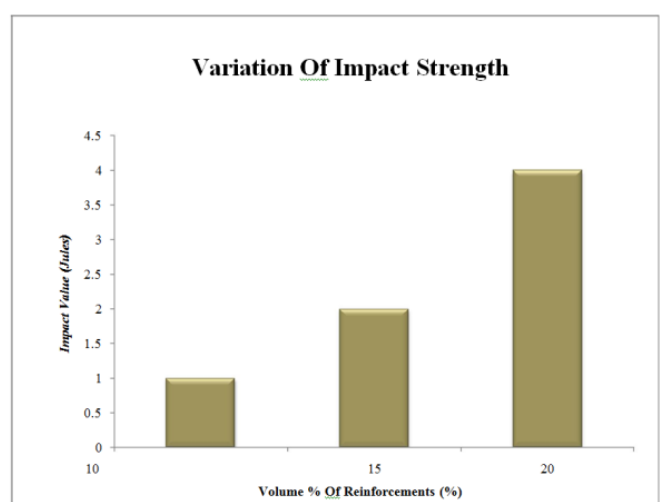

Fig. 4: Graphical Representation of Impact Values.

Table 5: Observation Table of Impact Strength Test.

\begin{tabular}{|c|c|}
\hline Volume \% of Reinforcements & Impact Value ( Joules ) \\
\hline 10 & 1 \\
\hline 15 & 2 \\
\hline 20 & 4 \\
\hline
\end{tabular}

Very poor impact strength is exhibited by the three samples which shows their brittle nature 
ASTM D785:-

ASTM D785 (Test Method for Hardness properties of polymers) is the hardness measuring standards. Rockwell hardness testing is a general method is used for bulk hardness of a material. Hardness testing is commonly used for evaluation of a material because of its simplicity and low cost compared to the direct measurement of the properties. The output doesn't have any units. Graphical representation of calculated values shown in fig.5

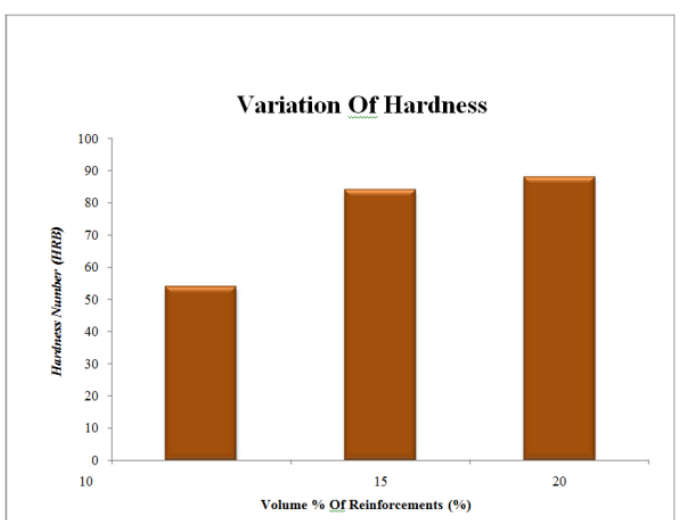

Fig. 5: Graphical Representation of Hardness Number.

Table 6: Observation Table of Hardness Test.

\begin{tabular}{|c|c|}
\hline Volume \% of Reinforcements & Hardness Number \\
\hline 10 & 54 \\
\hline 15 & 84 \\
\hline 20 & 88 \\
\hline
\end{tabular}

Due to high brittleness, all the test specimens have high hardness number. $20 \%$ sample shows the maximum hardness because that sample contains highest amount of reinforcements and reinforcements are responsible for the increase in hardness.

\section{ASTM D570}

ASTM D570 (Test Method for Water Absorption properties of polymers) is the method for water absorption properties. Water absorption is used to determine absorption rate of water under specified conditions. Type of plastic, additives used, temperature and length of exposure are the factors affecting water absorption.

In this test, using an oven for dried the sample in specified time and temperature. Then placed in desiccators get natural temperature and immediately the specimens are weighed. After that the material is keeping $23^{\circ} \mathrm{C}$ for 24 hours or equilibrium. Specimens are removed and patted dry with a free cloth then weighed. Graphical representation of calculated values shown in fig.6

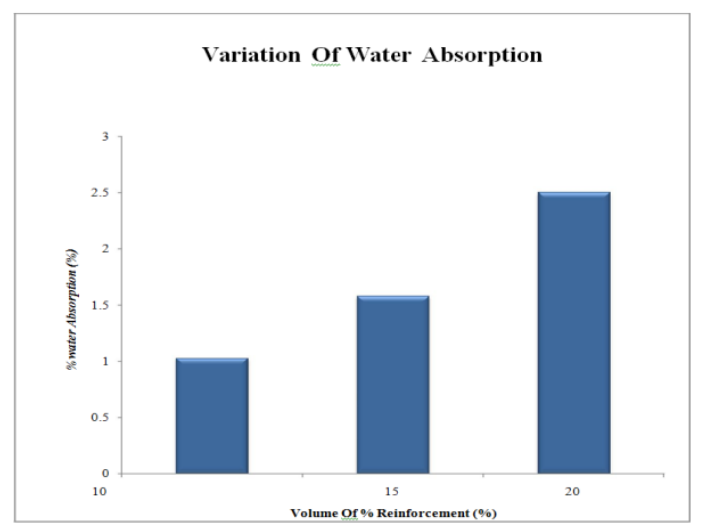

Fig.6: Graphical Representation of Percentage Water Absorption. 
Table 7: Observation Table of Water Absorption Test.

\begin{tabular}{|c|c|c|c|}
\hline Volume \% of Reinforcements & Dry Weight ( g ) & Wet Weight ( g ) & Water Absorption ( \% ) \\
\hline 10 & 1.95 & 1.97 & 1.025 \\
\hline 15 & 1.9 & 1.93 & 1.578 \\
\hline 20 & 2 & 2.05 & 2.5 \\
\hline
\end{tabular}

Very poor water absorption properties are exhibited by all the three samples. Percentage water absorption is increased slightly by the addition of reinforcements because the coir fiber and coconut shell powder are hydrophilic in nature.

\section{Conclusion:-}

In this work carried out to investigate the effect of amount of randomly oriented coir fiber and coconut shell powder in the matrix and to find out the governing mechanical properties of the hybrid composite. The effects of volume fraction of reinforcements on mechanical properties of composite were studied. The results found that the mechanical properties polyester hybrid composite have a strong association with the amount of reinforcements. And successful fabrication of a coir fiber and coconut shell reinforced polyester composites with different volume fractions are possible by simple hand lay-up technique.

\section{References:-}

1. Asasutjarit C, Hirunlabh J, Khedari J, Charoenchai S, Zeghmi S B, Shin C C - 2007, Development of coconut coir-based lightweight cement board. Construction Build Mater, Vol- 21, 277-88

2. Avella M, Buzarovska A, Errico M E, Gentile G, Grozdanov A - 2009, Eco-challenges of Bio based Polymer, Composites Materials Journals, Vol-3, Page 911-925.

3. Chowdhury A, Kumar S, Adhikari B - 2007, Polyethylene/linear low-density polyethylene based coir fiber composites, Journal of Applied Polymer Science, Vol- 106, Page 775-785.

4. Hill C A S, Khalil H P S A - 2000, Effect of fiber treatments on mechanical properties of coir and oil palm fiber reinforced polyester composites, Journal of Applied Polymer Science, Vol- 78/1685.

5. Hill C A S, H P SA Khalil - 2000, The effect of environmental exposure on the mechanical properties of coir or oil palm fiber reinforced composites, Journals of Applied Polymer Science, Vol-77/1322.

6. Joshi S, Mohanty S A, Drzal L T - 2003, Are Natural Fibre Composites Environmentally Superior to the Glass fibre Reinforced composites?, Journal of Composites -Applied Science And Manufacturing, Vol- 35, Page 371-376.

7. Karnani R, Krishnan M, Narayan R - 1997, Biofiber-reinforced polypropylene composites, Journals of Polymer Engineering and Science, Vol- 37(2), Page-476-483.

8. Khedari J, Suttisonk B, Pratintong N, Hirunlabh J - 2002, New lightweight composite construction materials with low thermal conductivity, Chemistry of Composite, Vol- 23, Page:65-70.

9. Owolabi O, Czvikovszky T, KovacsI - 1985, Coconut-fiber-reinforced thermosetting plastics, Journal of Applied Polymer Science, Vol - 30, Page:1827-1836.

10. Prasad S V, C Pavithram, P K Rohatgi - 1983, Alkali treatments of coir fibres and coir-polyester composites, Journal of Material Science, Vol- 18, Page-1443.

11. Route J, M Misra, A K Mohanty, S K Nayak, S S Tripathy - 2003, SEM observations of the fractured surfaces of coir composites, Journal of Reinforced Plastic Composite, Vol-22, Page: 1083.

12. Route J, M Misra, S S Tripathy, S K Nayak, A K Mohanty - 2001, The influence of fibre treatment on the performance based on coir-polyester composites, Composite Science and Technology, Vol- 61, Page:1303.

13. Sathynarayana K G, K Pillai, C K S. Sukumaran, C K S. Pillai, S G K. Rohatgi, P K Vijayan - 1982, Structure property studies of fibre, Journal of Materials Science, Vol- 17, Page -2453-2462.

14. Satyanarayana K G, K Sukumaran, A G Kulkarni, S G K Pillai, P K Rohatgi - 1986, Fabrication and properties of natural fibre-reinforced polyester composites, Journal of Composites, Vol -17, Page:329

15. www.astm.org/Standard/ 